\title{
ACCESSORY THYROID GLAND WITH DUAL BLOOD SUPPLY: A RARE VARIATION
}

\author{
Sanjula Singh, Archana Rani, Jyoti Chopra, Navneet Kumar, Manjula Singh \\ Department of Anatomy, King George's Medical University, Lucknow, UP, India
}

\begin{abstract}
A rare congenital anomaly of thyroid gland due to developmental defect is accessory or ectopic thyroid gland. Ectopic thyroid refers to the presence of thyroid tissue in locations other than the normal in anterior neck region between the second and fourth tracheal cartilages. Abnormal organogenesis of the thyroid gland leads to morphological variations, such as thyroid dysgenesis, hypoplasia, hemiagenesis and agenesis. The ectopic or accessory thyroid being the most common form of thyroid dysgenesis. Here, we are presenting a case with the accessory thyroid tissue with dual blood supply observed during a routine dissection of a female cadaveric body. The accessory thyroid tissue was in the form of an oval structure about $1.5 \mathrm{~cm} \times 3 \mathrm{~cm}$ was situated in the midline $2 \mathrm{~cm}$ above the normally located thyroid gland which was supplied by a branch of lingual artery as well as superior thyroid artery. The accessory thyroid tissue could be asymptomatic or it could present with any disorder affecting the main thyroid gland including malignancy. The significance of this case is to show an anatomical variation in the form of developmental defect during the organogenesis of thyroid along with its clinical implications. Thus, this report highlights the importance of knowing and understanding the normal anatomy of thyroid as well as the anatomical variant that could be immensely beneficial while diagnosing thyroid disorders or carrying out surgical procedures involving thyroid.
\end{abstract}

Keywords: Accessory thyroid gland, superior thyroid artery, lingual artery, variation.

\section{INTRODUCTION}

The thyroid gland is brownish -red endocrine gland situated anteriorly in the lower neck level with the C5T1.The gland consist of right and left lobe connected by a narrow isthmus. It weighs about $25 \mathrm{gm}$ and each lobe measures about $5 \mathrm{~cm} \times 3 \mathrm{~cm} \times 2 \mathrm{~cm}$ and isthmus $1.25 \mathrm{~cm} \times 1.25 \mathrm{~cm}$. The thyroid gland is slightly heavier in female and enlarged during menstruation and pregnancy. The thyroid gland is supplied by the superior and inferior thyroid arteries. The superior thyroid, lingual, and facial arteries arise from anterior surface of external carotid artery and the inferior thyroid artery is a branch of thyrocervical trunk (which arises from subclavian artery) [1]. The thyroid gland is a highly vascularized endocrine gland that frequently present with varied range of morphological anomalies [2]. Ectopic thyroid tissue is rare but may be found around the course of the thyroglossal duct due to arrest of migration along the line of descent or laterally in the neck, sometimes small detached masses of thyroid tissue may occur above the lobes or isthmus as accessory thyroid glands. Ectopic thyroid has a gender predisposition with male to female ratio of $1: 4$ [3-6]. Like other great vessels of neck, the external carotid artery and its branches have numerous variations and their exploration is more than interesting for a better anatomical knowledge of neck. These variations pose a dangerous situation during surgeries like thyroidectomy, laryngectomy facio-maxillary surgeries, tonsillectomy, glossectomy and other neck surgeries. It is important for the elevation of various cutaneous and myocutaneous flaps for plastic and reconstructive surgeries of the head, neck and face, which depend on the external carotid artery for their blood supply [7]. 


\section{CASE REPORT}

A rare congenital anomaly, accessory thyroid gland was found $2 \mathrm{~cm}$ above the superior border of hypertrophic, normally located thyroid gland which was having dual blood supply in a 60 years old female cadaver during routine dissection in the Department of Anatomy, King George's Medical University, Lucknow, Uttar Pradesh, India. The history of the individual and the cause of death was not known. The topographic details of thyroid and accessory thyroid was examined by casual dissection and photographed. The accessory thyroid gland was $2.5 \times 1.5 \mathrm{~cm}$ in size. As thyroid gland was supplied by superior and inferior thyroid arteries. The superior thyroid artery gives a branch to the accessory thyroid gland and a descending branch of lingual artery also supplied the accessory thyroid gland (Fig. 1).

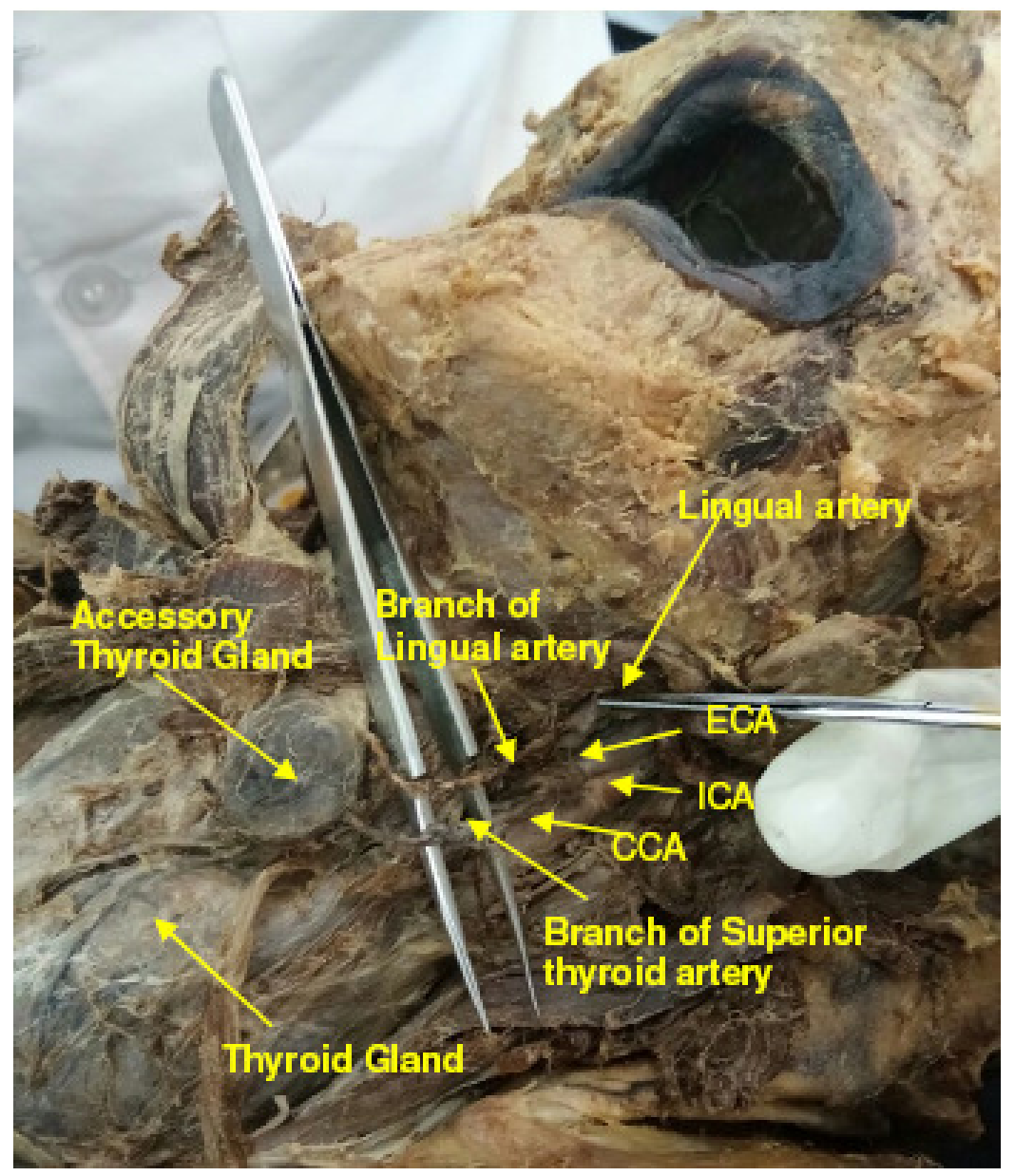

Fig. 1: Photograph showing thyroid and accessory thyroid glands supplied by branches of lingual artery and superior thyroid arteries (ECA-external carotid artery, ICA-internal carotid artery, CCA-common carotid artery)

\section{DISCUSSION}

Ranade et al (2008) noted an accessory thyroid tissue with absent isthmus in 1 case on male cadaver [8]. Nikumbh et al. (2015) found multiple thyroid anomalies like agenesis/absent isthmus with left pyramidal lobe and accessory lobe in between two lateral lobes with levator glandulae thyroidae in their case report [9]. Sawant et al. (2018) presented a case of dual thyroid in the form of ectopic or accessory thyroid tissue along with normal location thyroid found during a routine 
dissection of a female cadaveric body, situated in the midline near the hyoid bone. It was located $10.2 \mathrm{~cm}$ superior to a normally located thyroid gland and consistent with the track of the thyroglossal duct [10]. In our case same findings were noted as an accessory thyroid lobe present $2 \mathrm{~cm}$ above normally placed thyroid with dual blood supply.

The thorough knowledge of anatomical variations of the thyroid gland is important as it is relevant in different types of thyroidectomy and tracheotomy. The risk of damage to parathyroid gland, recurrent laryngeal nerve and hematoma due to vascular damage can be minimized by the knowledge of anatomical variation of the thyroid gland [11]. Base of foramen caecum is the most common location for the ectopic thyroid present as a mass in the dorsum of the tongue referred as lingual thyroid. Most of the variations of the thyroid gland are due to a partial persistence of the median or thyroglossal duct [12].

Ectopic thyroid is the most common cause of congenital hypothyroidism in infants [13]. It is the most frequent form of thyroid dysgenesis, accounting for $48-61 \%$ of the cases [14]. The majority of patients with ectopic thyroid are asymptomatic, while some cases are detected incidentally. Epidemiologically, ectopic thyroid tissue is a sporadic embryological deformity that is usually noticed during autopsy and that has a prevalence of up to $10 \%$ [15].

\section{CONCLUSION}

The knowledge of variation in the thyroid gland and its blood supply is important for surgical procedures in the neck region such as radical neck dissection, catheterization, reconstruction of aneurysm, and interventional radiology. These variations pose a dangerous situation during various neck surgeries. In this case report, we have presented a photographic evidence of ectopic thyroid gland and its dual blood supply in the anterior neck in a female cadaver along with a brief review summarizing important facts of normally located thyroid gland and ectopic thyroid.

\section{REFERENCES}

1. Standring $S$, Johnson $D$, Ellis $H$, Collins $P$ (eds). Gray's Anatomy, $39^{\text {th }}$ ed. Churchill Livingstone: London. 2005, pp. 543-544.

2. Rajkonwar AJ, Kusre G. Morphological variations of the thyroid gland among the people of upper Assam region of Northeast India: A cadaveric study. J Clin Diagn Res. 2016; 10(12):AC01AC03.

3. De Felice M, Di Lauro R. Thyroid development and its disorders: genetics and molecular mechanisms. Endocr Rev. 2004; 25(5):722-746

4. Kousta E, Konstantinidis K, Michalakis C, Vorias M, Sambalis G, Georgiou M, Theodoropoulos GE. Ectopic thyroid tissue in the lower neck with a coexisting normally located multinodular goiter and brief literature review. Hormones (Athens) 2005; 4(4):231-234

5. Noussios G, Anagnostis P, Goulis DG, Lappas D, Natsis K. Ectopic thyroid tissue: anatomical, clinical, and surgical implications of a rare entity. Eur $\mathrm{J}$ Endocrinol. 2011; 165(3):375-382

6. Ibrahim NA, Fadeyibi IO. Ectopic thyroid: etiology, pathology and management. Hormones (Athens). 2011; 10(4):261-269.

7. Strauch B, Vasconez LO, Hall Findlay EJ. Grabb's Encyclopedia of flaps. $2^{\text {nd }}$ ed., Vol 1. Head and Neck. Philadelphia: Lippincott-Raven, 1998, pp. 989-997.

8. Ranade AV, Rai R, Pai MM, Nayak SR, Krishnamurti A, Narayan S. Anatomical variations of the thyroid gland: possible surgical implications. Singapore Med J.2008; 49(10):831-834

9. Nikumbh RD, Nikumbh DB, Doshi MA. Multiple morphological variations in the thyroid gland: report of two cases. IJAR. 2015; 3(4):1476-80.

10. Sawant DA, Moore TF, Cashell AW. A cadaveric case report of dual thyroid: ectopic and normal location thyroid with brief review of literature. Endocrine and metabolism international $\mathrm{J}$. 2018; 6(3): 201-206.

11. Prakash, Rajini T, Ramchandran A, Savalgi GB, Venkata SP, Mokhasi V. Variations in the anatomy of the thyroid gland: clinical implications of a cadaver study. Anat Sci Int. 2012; 87 (1): 45-49.

12. Melnick JC, Stemkowski PE. Thyroid hemiagenesis (hockey sick sign): a review of world literature and a report of four cases. J Clin Endocrinol Metab.1981; 52:247-51.

13. Yoon JS, Won KC, Cho IH, Lee JT, Lee HW. Clinical characteristics of ectopic thyroid in Korea. Thyroid. 2007; 17 (11): 1117-1121.

14. Felice MD, Lauro RD. Thyroid development and its disorders: genetic and molecular mechanisms. Endocr Rev. 2004; 25 (5): 722-746.

15. Sawant DA, Moore TF, Cashell AW. A cadaveric case report of dual thyroid: ectopic and normal location thyroid with brief review of literature. Endocrinol Metab Int J. 2018; 6(3):201-206. 